\title{
The Suspicious Factors in Electronic Word-of-Mouth Communication
}

\author{
Xiao (Jerry) Zhang \\ Lamar University \\ Cynthia Barnes \\ Lamar University
}

\begin{abstract}
Electronic word-of-mouth (eWOM) has become influential on the Internet. As more incidents of using fake eWOM have been exposed, Internet users have developed various levels of suspicion toward eWOM communications. This exploratory study investigated Internet users' perceptions under the scope of suspicion and distrust. We were interested in how eWOM skepticism influences Internet users' selection of factors that indicate fake reviews. The findings reveal that Internet users with higher levels of eWOM skepticism are more likely to perceive more factors as indicators of fake reviews and tend to choose the conditions that are not very intuitive.
\end{abstract}

\section{INTRODUCTION}

Since the introduction of Web 2.0, electronic word of mouth (eWOM) has become more popular and has been used extensively on various online platforms. Within consumer behavior-related research, it's been investigated as an influential factor in brand recognition (M. Lee, Rodgers, \& Mikyoung Kima, 2009), vendor evaluation (Chatterjee, 2001), product preference (Vermeulen \& Seegers, 2009), and purchase behaviors (Dellarocas, Zhang, \& Awad, 2007). eWOM messages can be published freely without effective quality assurance controls (Flanagin \& Metzger, 2000; Johnson \& Kaye, 1998), and their vulnerability can be exploited by many organizations, public relation firms, and individuals to falsify communications among ordinary Internet users (Ahuja, Michels, Walker, \& Weissbuch, 2007; Carl, 2006). The aforementioned activities are referred to as online astroturfing, which is the "dissemination of deceptive opinions by imposters posing as autonomous individuals on the Internet with the intent of promoting a specific agenda" (Zhang et al., 2013, P. 3). As Internet users realize the increasing possibilities of encountering intentionally falsified eWOM messages (Forrest \& Cao, 2010; Malbon, 2013), their expectations during eWOM communications could be negative, developing skepticism toward all eWOM communications (X. J. Zhang, Ko, \& Carpenter, 2016). These types of skepticism are only tied to eWOM situations, called eWOM skepticism, and its levels are almost normally distributed among Internet users (X. J. Zhang et al., 2016).

Even though the terms "suspicion" and "skepticism" have hardly been mentioned by several researchers, these terms have never been theoretically assumed to mean "preexisting conditions" of Internet message recipients, and it seems that most prior research was based on the assumption that Internet users would be expecting favorable consequences from eWOM (C. Cheung \& Thadani, 2012; 
Jensen, Averbeck, Zhang, \& Wright, 2013) because the original purpose of eWOM messages was meant to be genuine and trustworthy. When Internet users are expecting negative consequences from the communication scenario (suspicion), their emotions and cognitive states could be very different (McKnight \& Chervany, 2001). With suspicion, Internet users may have feelings of insecurity, and they tend to interpret others' motives as rival and harmful, without any concrete evidence (Fein, 1996; Fein \& Hilton, 1994; Hilton, Fein, \& Miller, 1993). Therefore, we believe that Internet users who are highly affected by skepticism may perceive eWOM messages very differently compared to those who have lower levels of suspicion. During the evaluation of the trustworthiness of eWOM messages, Internet users were relying heavily on the cues that they picked up in the messages (C. Cheung \& Thadani, 2012). Many of these message cues (such as argument quality, message valence, and etc.) were intensively investigated in trust-related literatures (e.g. Awad and Ragowsky 2008; Cheung et al. 2008, 2009). However, in the present research, under the scope of distrust, we argue that they may be perceived differently by Internet users because of very different emotions and cognitive states. Moreover, with this condition, a person's judgment can be biased, thus taking some cues in the messages as indications of malicious motives. When people sense higher levels of risk in the environment, distrust-related factors could be more influential than they are in lower-risk conditions (McKnight \& Choudhury, 2006). This research is significantly distinguished from previous research by investigating the eWOM issues under the scope of suspicion and distrust. More specifically, we would like to answer two questions in this study:

\section{RQ 1: What kind of message cues are likely to be perceived as signs of fake reviews by Internet users?}

$\boldsymbol{R Q}$ 2: Would highly suspicious Internet users perceive more signs of fake reviews than low suspicious Internet users?

\section{LITERATURE REVIEW}

Lewicki et al. (1998) categorized trust and distrust by perceived intentions. Their definitions are very similar to Deutschi's (1960), which was that trust is "positive expectations regarding another's conduct," and distrust is "negative expectations regarding another's conduct" (Lewicki et al., 1998, p. 439). They further explain that the "positive expectation" refers to the belief in other people's beneficial and moral intentions, and the "negative expectations" refers to the belief in potential fraudulent intentions.

Burgoon and Walther (1990) asserted that when one person is communicating with others, people usually have preexisting expectations regarding others' behaviors. In recent years, as more evidence demonstrating the pervasive use of online astroturfing has been identified (Forrest \& Cao, 2010; Malbon, 2013), many people believe that they have seen or been deceived by fake eWOM messages (X. J. Zhang et al., 2016). According to Bond et al. (1992), when a behavior violates a nonverbal normative expectation, it will be seen as deceptive. Clearly, in many cases, the original purposes of eWOM have been abused. According to the Expectancy Violation Model (EVM) (Burgoon \& Hale, 1988), when norms are violated, the violations of expectations raise suspicion and create doubts. As a result, Internet users' confidence regarding the truthfulness and genuineness of eWOM communications have been severely undermined, and various levels of eWOM skepticism have been raised (X. J. Zhang et al., 2016).

A violation of expectations raises suspicion, which can lead to increased examination of the normviolating behaviors (Bond et al., 1992; Fein, 1996). Thus, when Internet users enter an eWOM situation with a suspicious attitude, they may actively seek and judge the factors that may indicate malicious intentions. However, suspicion may also induce cognition biases affecting their judgments (Kramer, 1994).

\section{Paranoid Cognition}

McKnight and Chervany (2001) argue that suspicion/distrust is associated with the feelings of insecurity regarding others' motivation or intention. When people are in a state of high levels of distrust, they usually feel fear and become paranoid, believing that they are exposed to risk of potential betrayal 
(Kramer, 1995; McKnight \& Chervany, 2001). When someone is in such a state, they may tend to take actions to mitigate the potential risks (McKnight \& Chervany, 2001). However, it is much more difficult when people cannot even identify whether the risks are present. In psychology research, Kramer (1998) conceptualized paranoid cognition, which is a process of exaggerated misattribution or over-attribution accompanied with distrust and suspicion. The interests of investigating paranoid cognition originated from clinical psychopathology, where such cognitions were recognized as a result of acute intrapsychic disturbance (Kramer, 1994). However, it is also believed that milder forms of paranoid cognitions can exist among normal individuals, suggesting that the consideration of paranoid cognition should be extended to thinking processes in everyday life (Fenigstein \& Vanable, 1992; Kramer, 1994; Zimbardo, Andersen, \& Kabat, 1981). There are three types of biases (Kramer, 1994) that are likely to be the results of paranoid cognition: 1) sinister attribution error, refers to a pattern of misattribution, where individuals misperceive the behavior or intentions of others and are overly suspicious of their intentions in the situation; 2) exaggerated perceptions of conspiracy refers to the tendency of over-attribute irreverent people's coherence and coordination (Pruitt, 1987); 3) overly personalistic construal of social interactions, refers to an individual's belief that he/she is the target of other people's behavior or thoughts (Kramer, 1998).

Holding the assumption that consumers are highly distrustful of sales people, Main et al., (2007) conducted a series of experiments investigating consumers' ratings for the trustworthiness of sales agents in different circumstances. In the experiment, the participants who were flattered after purchasing the product or service (when there would not be any direct benefit for the sales person from the flattery) still had significantly lower perceptions of trustworthiness toward the sales person than the participants who were not flattered at all. The authors assert that the lower perceptions of trustworthiness toward the sales person provided evidence for paranoid cognition made by the participants.

The necessary factors of forming paranoid cognition is that a person's concern regarding others' harmful intention without sufficient evidence or indication, perceptions about other's trustworthiness with unjustified doubts, and reluctance to rely on others was due to unwarranted fear about malicious motives (Robins, 1997). As the result of paranoid cognition, individuals may be overly or irrationally suspicious in certain situations, leading to persistent perception biases. Simply said, with paranoid cognition, people are very likely to take some situational cues as signs of harmful thoughts or intention of others.

\section{eWOM Skepticism}

Even though eWOM situations have never been studied as a context of paranoid cognition, eWOM situations seem a suitable way to form such cognition biases. First, after being exposed to different online astroturfing incidents, Internet users should realize the massive deception from online reviews, and they might be getting suspicious toward all eWOM communications. However, they do not know if or when the deceptive messages will be presented. Second, in most eWOM platforms, the identities of the message posters are not real; therefore, their trustworthiness may not be assured. Therefore, Internet users can be very hesitant to rely on the information from eWOM platforms. eWOM skepticism refers to Internet users' pre-dispositional suspicion and distrust towards all types of eWOM communications (X. J. Zhang et al., 2016). As a perception of the entire communication environment, eWOM skepticism should be relatively stable across different eWOM scenarios and only applied to the eWOM context, not other contexts like traditional advertising (McKnight \& Chervany, 2002). eWOM skepticism can be formed through time, based on Internet users' experience and knowledge regarding fake reviews.

Besides eWOM skepticism, there are many other factors, which can be personal, contextual, or situational that can also influence Internet users' judgment/perception toward received messages (C. Cheung \& Thadani, 2012; Gefen, Karahanna, \& Straub, 2003; McKnight, Choudhury, \& Kacmar, 2002). In the present study, we are interested in situational factors, more specifically, the cues in eWOM messages. These are the factors associated with the interaction process between each set of trustor and the trustee (Grabner-Kräuter \& Kaluscha, 2003; Kim, Song, Braynov, \& Rao, 2005; McKnight \& Chervany, 2002). During communication occasions, if a situational cue breached people's presupposition or expectations, they may perceive the situation as not-normal/suspicious and then their trust regarding 
the transaction will be questioned (Garfinkel, 1963). For instance, in the off-line setting, when consumers go to a physical store for shopping, if the store does not look like a store, the product does not look normal, or the salesperson does not behave naturally, the customer may perceive the situation as questionable and tend to be suspicious (Gefen et al., 2003).

Thus far, most of the studies that have investigated the credibility and trust issues associated with eWOM were mainly focused on situational level factors. More specifically, they focused on the characteristics of the message itself such as argument quality (Awad \& Ragowsky, 2008; C. Cheung et al., 2008, 2009), message valence (Gauri, Bhatnagar, \& Rao, 2008; J. Lee \& Lee, 2009; M. Lee \& Youn, 2009), sidedness (M.-Y. Cheung, Luo, Sia, \& Chen, 2009; Doh \& Hwang, 2009), consistency (C. Cheung et al., 2009), confirmation with a prior belief (M.-Y. Cheung et al., 2009) and Expertise (W. Zhang \& Watts, 2008). These factors used to be investigated by examining how these factors enhance the Internet users' positive attitude/perception toward the message or the topic. In other words, only the positive effects were considered for these factors in previous eWOM studies. Since the same factors can predict trust and distrust very differently (Lewicki et al., 1998; McKnight \& Choudhury, 2006), we believe that under the theme of suspicion, Internet users may view these factors differently (RQ 1).

According to Kramer's (1998) paranoid cognition model, we believe that in online context, highly skeptical Internet users can be overly suspicious when they read eWOM messages, and that such suspicions can induce cognition biases which may lead to irrational judgment on message cues. Even though it is hard to find any concrete evidence proving how genuine the message is, Internet users will still try to assess the credibility of the message or its sender and make inferences by relying on the cues they picked up in the communication (Dou, Walden, Lee, \& Lee, 2012). Our rationale is that since highly skeptical Internet users might be influenced/biased by their pre-existing negative attitude toward the entire communication context (eWOM skepticism), they might be excessively vigilant when they determine the cues that can help their judgment. As a result, they could view any factor as a sign of astroturfing. However, the same factor may be normal to the Internet users with lower levels of suspicion. Thus, to answer RQ 2:

We hypothesize that: eWOM skepticism is positively related to the number of factors that are seen as signs of fake reviews.

In addition to that, we would like to investigate what kind of situational cues are more likely to be judged as signs of online astroturfing.

\section{Factors in eWOM Situations}

Significant efforts have been spent to investigate what kind of factors are correlated to trust in eWOM situations.

Argument quality refers to the strength of the persuasive argument presented in the message. Simply put, it represents the overall content quality of the message. Usually, it is studied from three aspects: accuracy, timeless, and relevance. Sometimes comprehensiveness is also considered as an indicator of argument quality. Previous studies indicate that argument quality is positively associated with message credibility and information adoption (M.-Y. Cheung et al., 2009; W. Zhang \& Watts, 2008)(Cheung et al 2018).

Message valence/Framing refers to how positive or negative the message is. Positively framed messages emphasize the strength or positive side of the topic/subject, suggesting people adopt, buy or be associated with the topic or subject. Negatively framed messages focus on the problems or negative aspect of the topic/subject, advocating people to avoid or dislike the topic/subject. Positive eWOM messages could impact purchase intention (Gauri et al., 2008). Past research also suggests that people pay more attention to negative messages and that negative messages have stronger influence in eWOM situations (M. Lee \& Youn, 2009), and it could be more influential than positive messages (Park \& Lee, 2009). Moreover, it is believed to be positively related to eWOM credibility.

Message sidedness refers to the kind of valanced information contained in the message. One-sided message advocates only positive or negative valanced information, while two-sided message presents 
both positive and negative valanced information. Existing eWOM studies suggest that two-sided messages are perceived more credible (Doh \& Hwang, 2009).

Message consistency, or recommendation consistency, refers to the extent to which one eWOM message is consistent with other eWOM messages regarding the same subject. It was believed that if the presented eWOM message is consistent with the opinions from most other users, the credibility will be perceived as high. Otherwise, the message recipient might be confused and perceive the message as less creditable (M.-Y. Cheung et al., 2009).

Confirmation with prior belief refers to the extent to which the received eWOM message is confirmed by the message recipients' existing knowledge and beliefs regarding the subject. Conventionally, it is believed that if the message recipient's belief is confirmed by the message, the message recipient is likely to perceive the message as credible. If the message disconfirms the prior belief, it may get discredited or rejected (M.-Y. Cheung et al., 2009).

Expertise refers to the perceived message sender's ability to provide reliable information (Senecal \& Nantel, 2004). Usually, it is studied with the perceived level of authoritativeness or competence. It was found that expert reviews have a greater impact on sales compared to other reviews $(\mathrm{Hu}$, Liu, \& Zhang, 2008). Sometimes, regular online reviews were considered more credible than expert recommendations (Huang \& Chen, 2006).

The previously discussed eWOM message factors were mostly found to have significant influences in eWOM situations. However, most studies are conducted under the theme of trust instead of distrust. The questions that were always asked are "Does this factor make Internet users trust the review, and, if so, how strong is its influence?" Instead, in this research, we would like to investigate eWOM from the prospect of "distrust" or "suspicion". Therefore, under the scope of distrust, we argue that even though these factors may have significant influence from a trust prospect, under the lens of suspicion, these influences may be very different regarding their direction or magnitude.

\section{RESEARCH METHODOLOGY AND DATA COLLECTION}

We used a descriptive/exploratory survey to discover whether the aforementioned factors can be perceived as triggers of suspicion in eWOM scenarios. Our survey was distributed on Amazon Mechanical Turk, resulting in 355 valid data points (see Table 1 for sample demographics pertaining to control variables.). As suggested, we have limited the participants to U.S. residents only (Steelman, Hammer, \& Limayem, 2014).

\section{TABLE 1}

SAMPLE DEMOGRAPHICS

\begin{tabular}{|l|l|l|l|}
\hline Gender & Online Review Usage & Age & Education \\
\hline $\begin{array}{l}\text { Male: } 191 \\
(53.8 \%)\end{array}$ & Never: 0 (0\%) & $18-24: 30(8.45 \%)$ & $\begin{array}{l}\text { Less than high school degree: } 1 \\
(0.28 \%)\end{array}$ \\
\hline $\begin{array}{l}\text { Female: } 164 \\
(46.2 \%)\end{array}$ & Sometimes: $78(21.97 \%)$ & $25-34: 136(38.31 \%)$ & $\begin{array}{l}\text { High school degree or equivalent: } 37 \\
(10.42 \%)\end{array}$ \\
\hline & $\begin{array}{l}\text { About half the time: } 72 \\
(20.28 \%)\end{array}$ & $35-44: 83(23.38 \%)$ & $\begin{array}{l}\text { Some college but no degree: } 66 \\
(18.59 \%)\end{array}$ \\
\hline & $\begin{array}{l}\text { Most of the time: } 147 \\
(41.41 \%)\end{array}$ & $45-54: 48(13.52 \%)$ & Associate degree: $38(10.7 \%)$ \\
\hline & Always: $58(16.34 \%)$ & $55-64: 38(10.7 \%)$ & Bachelor's degree: $153(43.1 \%)$ \\
\hline & & $65-74: 20(5.63 \%)$ & Master's degree: $50(14.08 \%)$ \\
\hline & 75 or order:0 $(0 \%)$ & $\begin{array}{l}\text { Doctoral degree:5 (1.41\%) } \\
\text { Professional degree (JC MD):5 } \\
(1.41 \%)\end{array}$ \\
\hline
\end{tabular}


In order to inform the participants that the study was in the theme of suspicion, the survey started with the set of scales measuring eWOM Skepticism (X. J. Zhang et al., 2016). It was a formative construct comprised of three sub-constructs: truthfulness of the message, motives of the message senders, and identities of the message senders. All nine items (three for each subconstruct) were measured on 7-point Likert scales ranging from "strongly disagree" to "strongly agree" $(1=$ Strongly Disagree, $2=$ Disagree, 3=Slightly Disagree, 4=Neutral, 5=Slightly Agree, 6=Agree, 7=Strongly Agree). We also asked a series of questions regarding the influential factors that might trigger suspicion of a review. For instance, for Argument Quality, the initial question was "When you read online reviews, does the Argument Quality (relevance, accuracy, timeliness, or comprehensiveness of the text), either good or bad, make you suspect that the review might be fake?" If the answer selected was "yes", the instructions directed the participant to another question asking for the degree to which the factor made the participant suspicious. For example, the question for Argument Quality was "More specifically, which level(s) of the Argument Quality (relevance, accuracy, timeliness, or comprehensiveness of the text) might make you suspicious?", and the answers were "very poor, poor, fair, good or very good). The answers were tailored for each different factor. The survey can be found in Appendix A at the end of the paper. As the purposes of the study were mainly exploratory, the participants were allowed to select more than one answer. Towards the end of the survey, we asked several demographic questions regarding the usage of eWOM, gender, education, and age.

\section{FINDINGS AND DISCUSSION}

Using a relatively new scale, the measurement items for eWOM skepticism were tested again. The Cronbach's alpha and composite reliability of all the sub-constructs exceeded the recommended threshold of 0.70 (Fornell \& Larcker, 1981; Nunnally, 1978). The eWOM skepticism scores of all the experiment participants are almost normally distributed ( see Figure 1), indicated by Skewness $=0.138$ and Kurtosis $=$ -0.316 (George \& Mallery, 2010), indicating that Internet users do have various levels of eWOM skepticism.

\section{FIGURE 1 EWOM DISTRIBUTION}

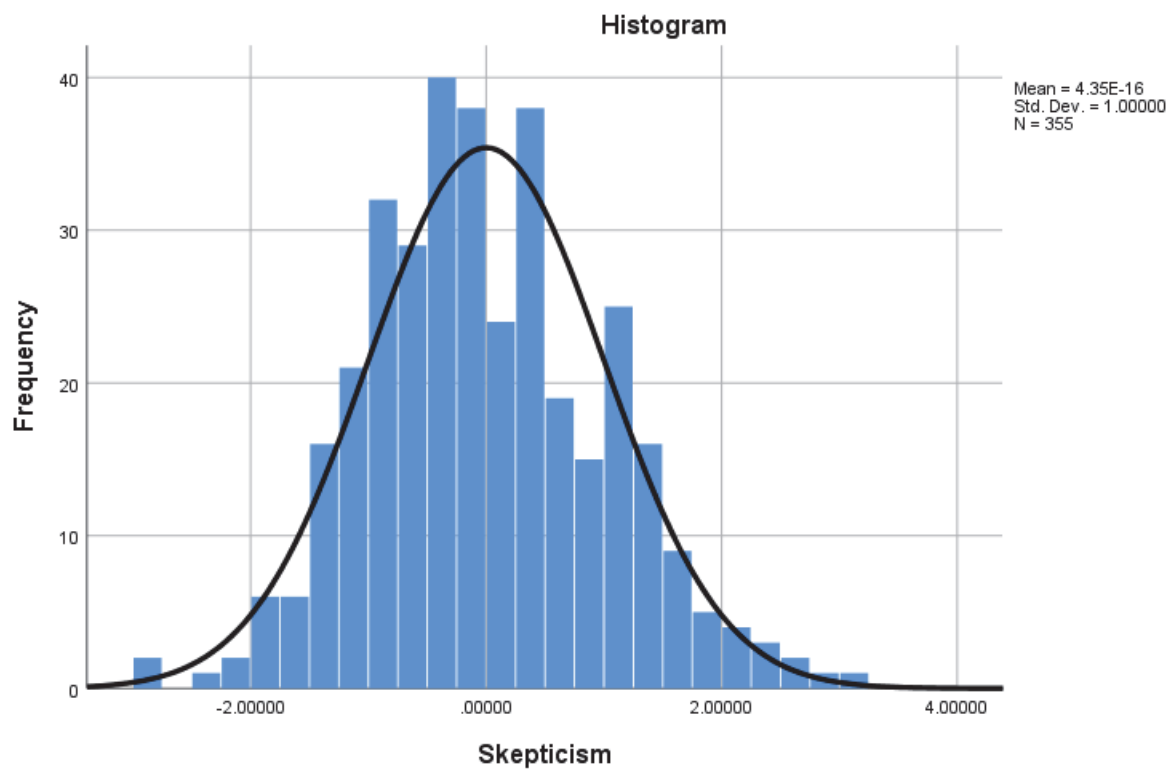


In order to test our hypothesis, we conducted a linear regression test (see Table 2 below). It included eWOM skepticism as an independent variable, and eWOM Usage, Gender, Education and age as control variables. The dependent variable was the total number of factors that each participant viewed as possible triggers for message suspicion. Since we investigated six factors in the survey, the dependent score ranged from 1 to 6 .

TABLE 2

LINEAR REGRESSION RESULTS

\begin{tabular}{|c|c|c|c|c|c|}
\hline \multirow[b]{2}{*}{ Model } & \multicolumn{2}{|c|}{$\begin{array}{l}\text { Unstandardized } \\
\text { Coefficients }\end{array}$} & \multirow{2}{*}{ 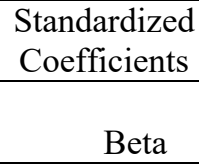 } & \multirow[b]{2}{*}{$\mathrm{t}$} & \multirow[b]{2}{*}{ Sig. } \\
\hline & $\mathrm{B}$ & $\begin{array}{l}\text { Std. } \\
\text { Error }\end{array}$ & & & \\
\hline (Constant) & 2.078 & .458 & & 4.534 & .000 \\
\hline Skepticism & .383 & .078 & .254 & 4.925 & .000 \\
\hline eWOM Usage & .274 & .076 & .184 & 3.590 & .000 \\
\hline Age & .007 & .058 & .006 & .125 & .901 \\
\hline Education & .074 & .058 & .066 & 1.279 & .202 \\
\hline Gender & .017 & .155 & .006 & .108 & .914 \\
\hline
\end{tabular}

As shown in Table 2, regarding the control variable gender (female was coded as 0 and male as 1), there was a non-significant correlation $(\beta=0.017, \mathrm{p}=.914)$ with the dependent variable. Also, both Age $(\beta$ $=0.07, \mathrm{p}=.901)$ and Education $(\beta=0.074, \mathrm{p}=.202)$ did not show any significant impact on suspicion factor count. eWOM usage were found to affect the dependent variable significantly $(\beta=0.274, p<.001)$. For the independent variable eWOM skepticism, the results of the regression indicated that it significantly predicted the number of factors that may induce suspicion $(\beta=0.383, p=. p<.001)$. Therefore, we can conclude that our hypothesis is supported and that more experienced eWOM users may view more factors as signs of fake reviews.

This result implies that if Internet users feel very unsafe about eWOM communications in general (high eWOM skepticism), they could be overly suspicious when they evaluate the eWOM messages. According to Paranoid Cognition, any noticeable cue in the message might be evaluated as a sign of fake reviews. As a result, the total number of these factors could be higher. On the contrary, Internet users with lower levels of eWOM skepticism may not believe the prevalence of eWOM abuses, so they might be less cautious and pick up fewer cues as an indication of astroturfing. We can also conclude that the magnitude of the influences from eWOM skepticism was very high and it can affect Internet users' decision-making processes in a large scale. To better understand the results and answer the rest of the research questions, a series of detailed analyses for each factor was conducted. The results are summarized in Table 3. 
TABLE 3

LOGISTIC REGRESSION RESULTS SUMMARY

\begin{tabular}{|c|c|c|c|}
\hline Factors & N of Yes & Percentage & Sig. \\
\hline Argument Quality & 318 & $89.58 \%$ & N/A \\
\hline Very Poor & 189 & $53.24 \%$ & $<.01$ \\
\hline Poor & 132 & $37.18 \%$ & $\mathrm{~N} / \mathrm{A}$ \\
\hline Fair & 21 & $5.92 \%$ & 0.058 \\
\hline Good & 18 & $5.07 \%$ & $<.01$ \\
\hline Very Good & 118 & $33.24 \%$ & $\mathrm{~N} / \mathrm{A}$ \\
\hline Message Valence & 228 & $64.23 \%$ & $<.01$ \\
\hline Positive & 187 & $52.68 \%$ & $<.01$ \\
\hline Negative & 99 & $27.89 \%$ & $\mathrm{~N} / \mathrm{A}$ \\
\hline Message Sidedness & 172 & $48.45 \%$ & 0.077 \\
\hline Only positive & 136 & $38.31 \%$ & N/A \\
\hline Only Negative & 78 & $21.97 \%$ & N/A \\
\hline Mostly positive with a few negative & 13 & $3.66 \%$ & $<.05$ \\
\hline Mostly negative with a few positive & 11 & $3.10 \%$ & $<.05$ \\
\hline Equal amount of positive and negative & 12 & $3.38 \%$ & $<.05$ \\
\hline Message consistency & 221 & $62.25 \%$ & N/A \\
\hline Positive consistent with majority & 43 & $12.11 \%$ & 0.067 \\
\hline Positive not consistent with majority & 154 & $43.38 \%$ & N/A \\
\hline Negative consistent with majority & 20 & $5.63 \%$ & $\mathrm{~N} / \mathrm{A}$ \\
\hline Negative not consistent with majority & 107 & $30.14 \%$ & $\mathrm{~N} / \mathrm{A}$ \\
\hline Confirmation with prior belief & 109 & $30.70 \%$ & $<.01$ \\
\hline Confirm existing belief & 41 & $11.55 \%$ & $<.01$ \\
\hline Disconfirm existing belief & 77 & $21.69 \%$ & N/A \\
\hline Expertise & 160 & $45.07 \%$ & $<.01$ \\
\hline Sounds like an expert & 100 & $28.17 \%$ & 0.069 \\
\hline Sounds like somewhat an expert & 32 & $9.01 \%$ & $<.01$ \\
\hline Sounds like new to the subject & 58 & $16.34 \%$ & 0.077 \\
\hline
\end{tabular}

Argument Quality was the factor that was selected most often as a sign of a fake review. Among the 355 participants, $318(89.58 \%)$ of them believed that Argument Quality can trigger their suspicion. In order to know whether it was related to Internet users' levels of suspicion, we conducted a logistic regression using eWOM skepticism as the independent variable (with control variables). Surprisingly, eWOM skepticism was not a significant predictor of choosing this factor. The levels of eWOM skepticism did not significantly predict whether the Internet user would suspect eWOM messages based on its argument quality, $b=0.245$, Wald $\chi^{2}(1)=1.697, p>.05$. However, Internet users who frequently used eWOM messages as references were very likely to use Argument Quality to evaluate the genuineness of the message, $b=0.353$, Wald $\chi^{2}(1)=3.94, p<.05$. Further, we were also interested in what types of Argument Quality that may seem questionable. Within 318 participants who chose Argument Quality as a suspicion factor, many of them stated that "very poor" $(189,39.54 \%)$ and "poor" Argument Quality" $(132,27.62 \%)$ can make them suspicious. This result was consistent with that of the previous literature: good Argument Quality can positively influence message credibility assessment (C. 
Cheung et al., 2008; W. Zhang \& Watts, 2008). Interestingly, one of the other options, "very good" (118, $24.69 \%$ ) Argument Quality could also make Internet users suspicious. One of the possible explanations could be that the time and effort reflected from a very high-quality review may look overly sophisticated and way beyond what a regular Internet user would do, causing people to question the possible incentives to do so. However, the participants who selected this option do not necessarily possess higher levels of eWOM skepticism. A separate logistic regression analysis showed that they are not significantly related $\left(b=0.077\right.$, Wald $\left.\chi^{2}(1)=0.444, p>.05\right)$. Meanwhile, "very poor" $\left(b=-0.297\right.$, Wald $\chi^{2}(1)=7.028, p<$ $.01)$, "fair" $\left(b=0.2434\right.$, Wald $\left.\chi^{2}(1)=3.583, p=.058\right)$ and "good" $\left(b=0.804\right.$, Wald $\chi^{2}(1)=10.154, p<$ $.05)$ Argument Quality can be perceived as triggers of suspicion for highly sceptical Internet users. It is worth mentioning that the coefficient of eWOM skepticism for "very poor" Argument Quality was negative. Since this was beyond the scope of this study, we hope that future experimental studies could provide detailed explanations.

Message valence/Framing was chosen by 228 (64.23\%) of the participants as a possible indicator of fake reviews. According to the results of the logistic regression analysis, whether Internet users would suspect an eWOM message by its valence can be predicted by the levels of eWOM skepticism $(b=0.57$, Wald $\left.\chi^{2}(1)=19.972, p<.01\right)$. The more Internet users worry about the entire communication context, the more likely they would suspect message valence. Message valence can be either positive or negative. Under the theme of trust, while positive messages may have a great impact on purchase intentions (Gauri et al., 2008), negative messages were usually perceived as diagnostic and informative, therefore, they are usually believed to be more truthful than positive reviews and have greater impact (M. Lee \& Youn, 2009; Park \& Lee, 2009). Our results were partially consistent with prior research; 187 participants believed that the overall positive attitude of the review can make them suspicious. These participants may be well aware that positive reviews can be used as a tactic to promote sales, since highly skeptical participants tend to see positive reviews as signs of astroturfing $\left(b=0.348\right.$, Wald $\left.\chi^{2}(1)=8.954, p<.01\right)$. Surprisingly, a noticeable number (99) of participants selected negative valence as a possible cue for fake reviews. Although it cannot be predicted by skepticism $\left(b=0.202\right.$, Wald $\left.\chi^{2}(1)=2.721, p>.05\right)$, it does notify us that Internet users were also aware of the possibility of using negative reviews to defame competitors. This result could prove a rich venue for future research.

An eWOM message may not provide only positive or negative information, it can also deliver both valence with various ratios. Message Sidedness was chosen by less than half of the participants (172, $48.45 \%$ ), and the result of the logistic regression with eWOM skepticism was very close to being significant at the .05 level $\left(b=0.202\right.$, Wald $\left.\chi^{2}(1)=2.721, p=.077\right)$. Within these participants, 136 of them stated that reviews with only positive opinions can make them suspicious, and 78 of them also suspect reviews with only negative opinions. Although none of these two options can be predicted by eWOM skepticism significantly, the results are consistent with that of the previous question regarding Message Valence. Interestingly, the rest of the choices were only selected by a very small percentage of the participants, "mostly positive with a few negative" (13), "mostly negative with a few positive" (11), and "about equal amount of positive and negative" (12). In trust-related research, the reviews with mostly positive but with a few negative points (8:2) were the most credible ones among other combinations (Doh \& Hwang, 2009). Because some of the Internet users do not trust the sincerity of pure positive messages, with the mindset that some entities were reportedly trying to manipulate the opinions of general consumers with intentional interventions in eWOM communication. That might explain why this option was chosen by only a few of our participants in this distrust-related study. All three of them can be predicted effectively by eWOM skepticism. Increasing eWOM skepticism was associated with the increased likelihood of choosing these three types of sidedness as signs of astroturfing. We believe this result also supports our hypothesis that Internet users with higher eWOM skepticism tend to view more cues as indicators of fake reviews.

Previous literature regarding eWOM credibility found that when an eWOM message is not consistent with other reviewers' opinions, the situation may arouse the reader's suspicion and the reader then may discredit the eWOM message (M.-Y. Cheung et al., 2009; Qiu, Pang, \& Lim, 2012). When the contradiction happens, the potential customer may believe that a) if it is a negative review, the message 
was probably sent by a competitor to intentionally denigrate the product or b) if it is a positive review, the message was sent by the vendor or the manufacturer of the product for promotion (Qiu et al., 2012). Our results regarding this factor are very consistent with these conclusions, with $221(62.25 \%)$ of the participants believing Message Consistency can make them suspicious. However, eWOM skepticism is not a significant predictor for choosing this factor $\left(b=0.202\right.$, Wald $\left.\chi^{2}(1)=2.721, p>.05\right)$. Among the options of Message Consistency, "positive opinion not consistent with the majority" (154) and "negative option not consistent with the majority" (107) were the most selected conditions that may trigger suspicion. In a series of logistic regression, we did not find eWOM skepticism as a strong predictor for most conditions, suggesting that no matter how Internet users may feel skeptical about eWOM communications, many of them are likely to view inconsistent reviews suspiciously. However, one of the results was unintuitive. "Positive consistent with majority", which should be less susceptible based on past research (M.-Y. Cheung et al., 2009; Qiu et al., 2012), was very likely to be chosen by the Internet users with a high skeptical attitude $\left(b=0.298\right.$, Wald $\left.\chi^{2}(1)=3.358, p=.067\right)$, suggesting the influences of Paranoid Cognition.

The levels of eWOM skepticism significantly predict whether the Internet user would suspect eWOM messages based on the reviews' Confirmation with prior belief (no matter yes or no) $(b=0.408$, Wald $\left.\chi^{2}(1)=11.228, p<.01\right)$, although only one-third $(109,30.70 \%)$ of our participants selected this factor. In trust-related literature, if the message confirms the reader's prior belief, the assessment of the message credibility would be higher. Our results also support this conclusion. Within the 118 participants who selected this factor, 77 of them admitted that the reviews disconfirming their existing beliefs can make them suspicious. At the same time, the levels of eWOM skepticism was not found to be related to this answer $\left(b=0.062\right.$, Wald $\left.\chi^{2}(1)=0.23, p>.05\right)$. Yet, we found a considerable number of participants (41) would still suspect the review even when it is confirming their existing beliefs, and these participants were very likely to have higher levels of eWOM skepticism $\left(b=0.688\right.$, Wald $\left.\chi^{2}(1)=15.255, p<.01\right)$.

Regarding the perceived Expertise of the message, trust-related literature has yielded mix results. It might have greater positive impact on purchasing behaviours than other reviews, or it might be considered significantly less trustworthy than regular consumer recommendations (Huang \& Chen, 2006). Our survey results indicate that expertise of a review can also raise suspicion. In this study, $160(45.7 \%)$ of the participants believed that the expressed expertise in a review can make suspect the authenticity of the review. Also, the levels of eWOM skepticism does significantly predict whether the Internet user would suspect eWOM messages based on this factor, $b=0.463$, Wald $\chi^{2}(1)=15.818, p<.01$. When we look at the results regarding the different conditions of this factor (expert, somewhat expert and non-expert), we found that the majority of them (100) suspect the reviews that sounded like they came from an expert. The logistic regression (with eWOM Skepticism) result is almost significant $\left(b=0.221\right.$, Wald $\chi^{2}(1)=$ $3.302, p=.069)$, indicating that Internet users with higher eWOM skepticism may have an increased likelihood of suspecting expert reviews. In addition, although the condition "somewhat an expert" was only chosen by 32 participants, they are very likely to be highly skeptical Internet users $(b=0.649$, Wald $\left.\chi^{2}(1)=11.138, p<.01\right)$, as well as the participants (58) who choose "non-expert" as a suspicion factor $(b$ $=0.255$, Wald $\left.\chi^{2}(1)=3.123, p=.077\right)$. These results suggest that while many of the Internet users won't judge the genuineness of the review based on the sounded expertise, highly skeptical Internet users will question the legitimacy of the reviews by any levels of expertise.

\section{CONCLUSIONS AND LIMITATIONS}

In the present study, we were interested in the effects of Internet users' suspicion toward eWOM communication context. More specifically, we focused on how eWOM skepticism influences the selection of factors that may be the bases of evaluating received eWOM messages. Since this investigation was conducted under the theme of suspicion, we surveyed 355 Internet users to ask whether the listed factors and their conditions may make them suspicious about reviews. Six factors, Augment Quality, Message Valence, Message Sidedness, Message Consistency, Confirmation with prior belief and Expertise, were included in the survey. While in previous literature these factors were studied as 
influential cues affecting Internet users' trust (positive attitude) toward the messages, we found that most Internet users would also use these factors to evaluate whether the messages might be fake, no matter their pre-existing negative perceptions. At the same time, significant influences from eWOM skepticism were observed. Internet users with higher levels of eWOM skepticism were likely to utilize more factors as indicators of fake reviews, compared to those with less suspicion. At the same time, regarding the conditions for each factor, highly skeptical Internet users also tend to choose the factors that are not very intuitive, such as "fair" and "good" Argument Quality, mixed Sidedness, "positive messages consistent with majority", "confirm" Prior Belief, and "somewhat" or "None" Expert. We believe that these results are the indications of the effects of Paranoid Cognition, which can be induced by high levels of suspicion.

Since the nature of this study was exploratory and the data were collected from a non-experimental self-report setting, the results should be interpreted with caution. The main goal of this investigation was to provide direction and meaningful questions for future research. We hope that follow-up studies can validate the results from this study using controlled experiments, investigating the determinative mechanisms associated with the factors and the magnitudes of their effects.

\section{REFERENCES}

Ahuja, R. D., Michels, T. A., Walker, M. M., \& Weissbuch, M. (2007). Teen perceptions of disclosure in buzz marketing. Journal of Consumer Marketing, 24, 151-159.

Awad, N. F., \& Ragowsky, A. (2008). Establishing Trust in Electronic Commerce Through Online Word of Mouth: An Examination Across Genders. Journal of Management Information Systems, 24, $101-121$.

Bond, C. F., Omar, A., Pitre, U., Lashley, B. R., Skaggs, L. M., \& T, C. (1992). Fishy-looking liars: Deception judgment from expectancy violation. Journal of Personality and Social Psychology, 63, 969-977.

Burgoon, J. K., \& Hale, J. L. (1988). Nonverbal expectancy violations: Model elaboration and application to immediacy behaviors. Communication Monographs, 55, 58-79.

Burgoon, J. K., \& Walther, J. B. (1990). Nonverbal Expectancies and the Evaluative Consequences of Violations. Human Communication Research, 17, 232-265.

Carl, W. J. (2006). What's all the buzz about? Everyday Communication and the Relational Basis of Word-of-Mouth and Buzz Marketing Practices. Management Communication Quarterly, 19, 601634.

Chatterjee, P. (2001). Online Reviews: Do Consumers Use Them? Advances in Consumer Research, 28, 129-133.

Cheung, C., Lee, M. K. O., \& Rabjohn, N. (2008). The impact of electronic word-of-mouth: The adoption of online opinions in online customer communities. Internet Research, 18, 229-247.

Cheung, C., Lee, M. K. O., \& Thadani, D. R. (2009). The Impact of Positive Electronic Word-of-Mouth on Consumer Online Purchasing Decision. In Visioning and Engineering the Knowledge Society. A Web Science Perspective (pp. 501-510). Springer Berlin Heidelberg.

Cheung, C., \& Thadani, D. R. (2012). The impact of electronic word-of-mouth communication: A literature analysis and integrative model. Decision Support Systems, 54, 461-470.

Cheung, M.-Y., Luo, C., Sia, C. L., \& Chen, H. (2009). Credibility of Electronic Word-of-Mouth: Informational and Normative Determinants of On-line Consumer Recommendations. International Journal of Electronic Commerce, 13, 9-38.

Dellarocas, C., Zhang, X. M., \& Awad, N. F. (2007). Exploring the value of online product reviews in forecasting sales: The case of motion pictures. Journal of Interactive Marketing, 21, 23-45.

Deutschi, M. (1960). The Effect of Motivational Orientation upon Trust and Suspicion. Human Relations, $13,123-139$.

Doh, S.-J., \& Hwang, J.-S. (2009). How Consumers Evaluate eWOM (Electronic Word-of-Mouth) Messages. CyberPsychology \& Behavior, 12, 193-197. 
Dou, X., Walden, J. A., Lee, S., \& Lee, J. Y. (2012). Does source matter? Examining source effects in online product reviews. Computers in Human Behavior, 28, 1555-1563.

Fein, S. (1996). Effects of suspicion on attributional thinking and the correspondence bias. Journal of Personality and Social Psychology, 70, 1164-1184.

Fein, S., \& Hilton, J. L. (1994). Judging others in the shadow of suspicion. Motivation and Emotion, 18, 167-198.

Fenigstein, A., \& Vanable, P. A. (1992). Paranoia and self-consciousness. Journal of Personality and Social Psychology, 62, 129-138.

Flanagin, A. J., \& Metzger, M. J. (2000). Perceptions of Internet information credibility. Journalism and Mass Communication Quarterly, 77, 515-540.

Fornell, C., \& Larcker, D. F. (1981). Evaluating Structural Equation Models with Unobservable Variables and Measurement Error. Journal of Marketing Research, 18, 39-50.

Forrest, E., \& Cao, Y. (2010). Opinions, recommendations and endorsements: The new regulatory framework for social media. Journal of Business and Policy Research, 5, 88-99.

Garfinkel, H. (1963). A conception of and experiments with "trust" as a condition of concerted stable actions. The Production of Reality: Essays and Readings on Social Interaction, 381-392.

Gauri, D. K., Bhatnagar, A., \& Rao, R. (2008). Role of word of mouth in online store loyalty. Communications of the ACM, 51, 89-91.

Gefen, D., Karahanna, E., \& Straub, D. W. (2003). Trust and TAM in Online Shopping: An Integrated Model. MIS Quarterly, 27, 51-90.

George, D., \& Mallery, P. (2010). SPSS for Windows Step by Step. A simple Guide and Reference, Boston, MA. USA: Ed.

Grabner-Kräuter, S., \& Kaluscha, E. A. (2003). Empirical research in on-line trust: a review and critical assessment. International Journal of Human-Computer Studies, 58, 783-812.

Hilton, J. L., Fein, S., \& Miller, D. T. (1993). Suspicion and Dispositional Inference. Personality and Social Psychology Bulletin, 19, 501-512.

Hu, N., Liu, L., \& Zhang, J. J. (2008). Do online reviews affect product sales? The role of reviewer characteristics and temporal effects. Information Technology and Management, 9, 201-214.

Huang, J.-H., \& Chen, Y.-F. (2006). Herding in online product choice. Psychology \& Marketing, 23, 413-428.

Jensen, M. L., Averbeck, J. M., Zhang, Z., \& Wright, K. B. (2013). Credibility of Anonymous Online Product Reviews: A Language Expectancy Perspective. Journal of Management Information Systems, 30, 293-324.

Johnson, T. J., \& Kaye, B. K. (1998). Cruising is believing? Comparing Internet and traditional sources on media credibility measures. Journalism \& Mass Communication Quarterly, 75, 325-340.

Kim, D. J., Song, Y. I., Braynov, S. B., \& Rao, H. R. (2005). A multidimensional trust formation model in B-to-C e-commerce: a conceptual framework and content analyses of academia/practitioner perspectives. Decision Support Systems, 40, 143-165.

Kramer, R. M. (1994). The sinister attribution error: Paranoid cognition and collective distrust in organizations. Motivation and Emotion, 18, 199-230.

Kramer, R. M. (1995). Divergent realities and convergent disappointments in the hierarchic relation. Trust in Organizations: Frontiers of Theory and Research, 216-245.

Kramer, R. M. (1998). Paranoid Cognition in Social Systems: Thinking and Acting in the Shadow of Doubt. Personality and Social Psychology Review, 2, 251-275.

Lee, J., \& Lee, J.-N. (2009). Understanding the product information inference process in electronic wordof-mouth: An objectivity-subjectivity dichotomy perspective. Information \& Management, 46, 302-311.

Lee, M., Rodgers, S., \& Mikyoung Kima. (2009). Effects of Valence and Extremity of eWOM on Attitude toward the Brand and Website. Journal of Current Issues \& Research in Advertising (CTC Press), 31, 1-11. 
Lee, M., \& Youn, S. (2009). Electronic word of mouth (eWOM). International Journal of Advertising, 28, 473-499.

Lewicki, R. J., McAllister, D. J., \& Bies, R. J. (1998). Trust and Distrust: New Relationships and Realities. The Academy of Management Review, 23, 438-458.

Main, K. J., Dahl, D. W., \& Darke, P. R. (2007). Deliberative and automatic bases of suspicion: Empirical evidence of the sinister attribution error. Journal of Consumer Psychology, 17, 59-69.

Malbon, J. (2013). Taking Fake Online Consumer Reviews Seriously. Journal of Consumer Policy, 36, $139-157$.

McKnight, D. H., \& Chervany, N. L. (2001). Trust and Distrust Definitions: One Bite at a Time. In R. Falcone, M. Singh, \& Y.-H. Tan (Eds.), Trust in Cyber-societies (pp. 27-54). Springer Berlin Heidelberg.

McKnight, D. H., \& Chervany, N. L. (2002). What trust means in e-commerce customer relationships: an interdisciplinary conceptual typology. International Journal of Electronic Commerce, 6, 35-60.

McKnight, D. H., \& Choudhury, V. (2006). Distrust and Trust in B2C e-Commerce: Do They Differ? In Proceedings of the 8th International Conference on Electronic Commerce (pp. 482-491). New York, NY, USA: ACM.

McKnight, D. H., Choudhury, V., \& Kacmar, C. (2002). Developing and validating trust measures for ecommerce: an integrative typology. Information Systems Research, 13, 334-359.

Nunnally, J. C. (1978). Psychometric theory (2nd ed.). New York: McGraw Hill.

Park, C., \& Lee, T. M. (2009). Information direction, website reputation and eWOM effect: A moderating role of product type. Journal of Business Research, 62, 61-67.

Pruitt, D. G. (1987). Conspiracy Theory in Conflict Escalation. In C. F. Graumann \& S. Moscovici (Eds.), Changing Conceptions of Conspiracy (pp. 191-202). Springer New York.

Qiu, L., Pang, J., \& Lim, K. H. (2012). Effects of conflicting aggregated rating on eWOM review credibility and diagnosticity: The moderating role of review valence. Decision Support Systems, 54, 631-643.

Robins, R. S. (1997). Political paranoia: The psychopolitics of hatred. Yale University Press.

Senecal, S., \& Nantel, J. (2004). The influence of online product recommendations on consumers' online choices. Journal of Retailing, 80, 159-169.

Steelman, Z. R., Hammer, B. I., \& Limayem, M. (2014). Data Collection in the Digital Age: Innovative Alterantives to Student Samples. Mis Quarterly, 38, 355-378.

Vermeulen, I. E., \& Seegers, D. (2009). Tried and tested: The impact of online hotel reviews on consumer consideration. Tourism Management, 30, 123-127.

Zhang, J., Carpenter, D., \& Ko, M. (2013). Online Astroturfing: A Theoretical Perspective. In Proceedings of the 19th Americas Conference on Information Systems (Vol. 4, pp. 2559-2565). Association for Information Systems.

Zhang, W., \& Watts, S. A. (2008). Capitalizing on Content: Information Adoption in Two Online communities. Journal of the Association for Information Systems, 9, 73-94.

Zhang, X. J., Ko, M., \& Carpenter, D. (2016). Development of a scale to measure skepticism toward electronic word-of-mouth. Computers in Human Behavior, 56, 198-208.

Zimbardo, P. G., Andersen, S. M., \& Kabat, L. G. (1981). Induced Hearing Deficit Generates Experimental Paranoia. Science, 212, 1529-1531. 


\section{APPENDIX A}

\section{SURVEY QUESTIONS}

\begin{tabular}{|c|c|}
\hline Construct & Item \\
\hline \multirow{3}{*}{$\begin{array}{l}\text { eWOM Skepticism } \\
\text { Truthfulness }\end{array}$} & We can hardly depend on getting the truth from most online reviews. \\
\hline & Online reviews are not generally truthful. \\
\hline & In general, online reviews don't reflect the true picture of a subject \\
\hline \multirow{3}{*}{$\begin{array}{l}\text { eWOM Skepticism } \\
\text { Motivation }\end{array}$} & Online reviewers care more about getting you to buy things. \\
\hline & Most online reviews are intended to mislead. \\
\hline & People writing online reviews are always up to something. \\
\hline \multirow{3}{*}{$\begin{array}{l}\text { eWOM Skepticism } \\
\text { Identity }\end{array}$} & People writing online product reviews are not necessarily the real customers. \\
\hline & People write online reviews pretending they are someone else. \\
\hline & Different reviews are often posted by the same person under different names. \\
\hline \multirow[b]{2}{*}{ Argument Quality } & $\begin{array}{l}\text { When you read online reviews, does the Argument Quality (relevance, accuracy, } \\
\text { timeliness, or comprehensiveness of the text), either good or bad, make you suspect } \\
\text { that the review might be fake? } \\
\text { Yes } \\
\text { No }\end{array}$ \\
\hline & $\begin{array}{l}\text { More specifically, which level(s) of the Argument Quality (relevance, accuracy, } \\
\text { timeliness, or comprehensiveness of the text) might make you suspicious? (you can } \\
\text { choose more than one answer) } \\
\text { very poor argument quality can make me suspicious } \\
\text { poor argument quality can make me suspicious } \\
\text { fair argument quality can make me suspicious } \\
\text { good argument quality can make me suspicious } \\
\text { very good argument quality can make me suspicious }\end{array}$ \\
\hline \multirow{2}{*}{ Message Valence } & $\begin{array}{l}\text { When you read online reviews, does the Recommendation Framing (overall } \\
\text { positive or negative attitude of the review) make you suspect that the review might } \\
\text { be fake? } \\
\text { Yes } \\
\text { No }\end{array}$ \\
\hline & $\begin{array}{l}\text { More specifically, what kind of the Recommendation Framing (overall positive or } \\
\text { negative attitude of the review) might make you suspicious? (you can choose more } \\
\text { than one answer) } \\
\text { the overall positive attitude of the review can make me suspicious } \\
\text { the overall negative attitude of the review can make me suspicious }\end{array}$ \\
\hline Message Sidedness & $\begin{array}{l}\text { A review may only include pros or cons regarding the subject (one-sided review), } \\
\text { but it may include both of them (two-sided review). It is called Review } \\
\text { Sidedness. When you read online reviews, does the Review Sidedness make you } \\
\text { suspect that the review might be fake? } \\
\text { Yes } \\
\text { No }\end{array}$ \\
\hline
\end{tabular}




\begin{tabular}{|c|c|}
\hline Construct & Item \\
\hline & $\begin{array}{l}\text { More specifically, what kind of Review Sidedness might make you suspicious? (you } \\
\text { can choose more than one answer) } \\
\text { review with only positive opinions can make me suspicious } \\
\text { review with only negative opinions can make me suspicious } \\
\text { review with mostly positive but a few negative opinions can make me suspicious } \\
\text { review with mostly negative but a few positive opinions can make me suspicious } \\
\text { review with about equal amount of positive and negative opinions can make me } \\
\text { suspicious }\end{array}$ \\
\hline \multirow[b]{2}{*}{ Consistency } & $\begin{array}{l}\text { No matter what types of opinions are presented in a review, they may or may not be } \\
\text { consistent with that of majority reviews. It is called Review Consistency. When you } \\
\text { read online reviews, does the Review Consistency make you suspect that the review } \\
\text { might be fake? } \\
\text { Yes } \\
\text { No }\end{array}$ \\
\hline & $\begin{array}{l}\text { More specifically, what kind of Review Consistency might make you suspicious? } \\
\text { (you can choose more than one answer) } \\
\text { positive opinion that are consistent with majority reviews can make me suspicious } \\
\text { positive opinion that are not consistent with majority reviews can make me } \\
\text { suspicious } \\
\text { negative opinion that are consistent with majority reviews can make me suspicious } \\
\text { negative opinion that are not consistent with majority reviews can make me } \\
\text { suspicious }\end{array}$ \\
\hline \multirow[t]{2}{*}{$\begin{array}{l}\text { Confirmation of } \\
\text { prior belief }\end{array}$} & $\begin{array}{l}\text { Before you read a review, you might already have formed your own opinions } \\
\text { regarding the discussed subject (such as a product or a person). However, the } \\
\text { opinions presented in the review could either confirm or disconfirm your beliefs. } \\
\text { Can this confirmation or disconfirmation make you suspect that the review might } \\
\text { be fake? } \\
\text { Yes } \\
\text { No }\end{array}$ \\
\hline & $\begin{array}{l}\text { More specifically, in which situation(s) you might feel suspicious? (you can choose } \\
\text { more than one answer) } \\
\text { the review confirms my existing beliefs about the subject can make me suspicious } \\
\text { the review disconfirms my existing beliefs about the subject can make me } \\
\text { suspicious }\end{array}$ \\
\hline \multirow{2}{*}{$\begin{array}{l}\text { Reviewer } \\
\text { expertise }\end{array}$} & $\begin{array}{l}\text { Sometimes, the reviewer claims him/her self as (or sounds like) very experienced } \\
\text { or expert in the subject area. Or, they may admit (or sounds like) that they are new to } \\
\text { the topic. } \\
\text { Does the expressed expertise in a review make you suspect that the review might be } \\
\text { fake? } \\
\text { Yes } \\
\text { No }\end{array}$ \\
\hline & $\begin{array}{l}\text { More specifically, in which situation(s) might you feel suspicious? (you can choose } \\
\text { more than one answer) } \\
\text { the reviewer who sounds like an expert or experienced can make me suspicious } \\
\text { the reviewer who sounds like somewhat of an expert or somewhat experienced can } \\
\text { make me suspicious } \\
\text { the reviewer who sounds like someone new to the subject can make me suspicious }\end{array}$ \\
\hline
\end{tabular}

